\title{
Zircônia pigmentada obtida pelo método Pechini para aplicações odontológicas
}

\author{
Pigmented zircônia-yttria obtained by \\ Pechini Method for dental applications
}

\author{
Naasson Matheus Pereira Balica ${ }^{1}$, Themistocles de Sousa Campelo², \\ Edson Cavalcante da Silva Filho ${ }^{1}$, Maria Rita de Morais Chaves Santos ${ }^{1}$, \\ Rafaela Luiz Pereira Santos ${ }^{1,3}$
}

\footnotetext{
${ }^{1}$ Programa de Pós-Graduação em Ciência e Engenharia dos Materiais, CT/UFPI, CEP: 64049-550, Teresina, PI, Brasil.

${ }^{2}$ Bacharelado em Engenharia de Materiais, CT/UFPI, CEP: 64049-550, Teresina, PI, Brasil.

${ }^{3}$ Departamento de Engenharia de Materiais - CT/UFPI, CEP: 64049-550, Teresina, PI, Brasil. e-mail: matheusbalica@ hotmail.com, themistocles777@outlook.com, edsonfilho@ufpi.edu.br, mrita@ufpi.edi.br, raffitasantos8@hotmail.com.
}

\begin{abstract}
RESUMO
A introdução da zircônia $\left(\mathrm{ZrO}_{2}\right)$ como material odontológico representa um grande avanço quando comparado aos demais materiais tradicionalmente utilizados para esta finalidade. Este material destaca-se, devido às suas ótimas propriedades tais como resistência mecânica e biocompatibilidade. No entanto, existem limitações quanto a sua coloração branca e alta opacidade, não sendo possível mimetizar as características da dentição humana, afetando assim o conceito estético desses materiais e diminuindo o conforto do paciente. Este trabalho propõe desenvolver pós de zircônia pigmentada através do método Pechini, dopando-os com óxido de ferro em diferentes concentrações $(3 \%, 2 \%, 1 \%, 0,5 \%, 0,25 \%$ em mol) e itria, posteriormente calcinálos a temperatura de $1000{ }^{\circ} \mathrm{C}$, com a finalidade de obter a mistura química mais efetiva, próxima da tonalidade da dentina humana. As amostras foram caracterizadas por Difração de Raios X (DRX), Microscopia Eletrônica de Varredura (MEV), Espectroscopia de Energia Dispersiva (EDS), teste de toxicidade e avaliação colorimétrica, confirmando a presença do ferro dentro da microestrutura da zircônia e suas modificações causadas no material. Os resultados indicam que os tamanhos de cristalitos dos pós sintetizados aumentaram de $35,45 \mathrm{~nm}$ para $48,97 \mathrm{~nm}$, quando a concentração de ferro aumentou de $0 \%$ para $3 \%$. Os espectros de EDS indicaram a presença de ferro em todas as amostras, com variadas concentrações do pigmento. O método utilizado foi efetivo para a produção de pós de zircônia com variadas nuances de cores, possuindo um grande potencial para aplicações odontológicas.
\end{abstract}

Palavras-chave: Zircônia pigmentada. Método Pechini. Odontológica.

\begin{abstract}
The introduction of zirconia $\left(\mathrm{ZrO}_{2}\right)$ as a dental material, represents a major advance when compared to other materials traditionally used for this purpose. This material stands out due to its excellent properties such as mechanical resistance and biocompatibility. However, there are limitations regarding its white color and high opacity, and it is not possible to mimic the characteristics of human dentition, thus affecting the aesthetic concept of these materials and reducing patient comfort. This work proposes to develop pigmented zirconia powders using the Pechini method, doping them with iron oxide in different concentrations (3\%, $2 \%, 1 \%$, $0.5 \%, 0.25 \mathrm{~mol} \%$ ) and itria, later calcine them at a temperature of $1000{ }^{\circ} \mathrm{C}$ in order to obtain the most effective chemical mixture, close to the shade of human dentin. The samples were characterized by X-ray Diffraction (XRD), Scanning Electron Microscopy (SEM), Energy Dispersive Spectroscopy (EDS), toxicity testing and colorimetric evaluation, confirming the presence of iron within the zirconia microstructure and its modifications caused in the material. The obtained results indicate that the crystallite sizes of the synthesized powders increased from $35,45 \mathrm{~nm}$ to $48,97 \mathrm{~nm}$ when the iron concentration increased from $0 \%$ to 3 mol\%. The EDS spectra indicated the presence of iron in all the samples, with varying concentrations of the pig-
\end{abstract}


mentant agent. The method used was effective for the production of zirconia powders with varied color nuances, having great potential for dental applications.

Keywords: Pigmented zirconia. Pechini method. Dental.

\section{INTRODUÇÃO}

A necessidade por qualidade estética no âmbito de próteses odontológicas vem impulsionando a geração de produtos ainda mais sofisticados. Os materiais cerâmicos têm apresentado bastante destaque na área odontológica como materiais restauradores [1]. As cerâmicas para uso odontológico precisam apresentar estabilidade química, alta resistência à compressão, biocompatibilidade e características estéticas compatíveis com a função definida. Outra característica que precisa ser observada é a possibilidade de formação de placas bacterianas no material, já que existem superfícies que dificultam a formação destas placas e que são de fundamental importância para longos períodos de uso [2].

Dentre os materiais cerâmicos mais utilizados para a odontologia, como: alumina [3, 4], hidroxiapatita [5], dissilicato de lítio [6] e porcelanas [7], a zircônia [8, 9] tem se consolidado como um material promissor, devido às suas diversas aplicações como biomaterial, possuir alta resistência mecânica e alta tenacidade à fratura, tornando-se um material básico para confecção de coroas dentárias e próteses fixas dentária, em restaurações dentárias, tendo em vista a crescente demanda estética e a preocupação com a hipersensibilidade de materiais metálicos $[10,11]$.

Devido à probabilidade de fraturas decorrentes da mudança de estrutura cristalina em temperatura ambiente (tetragonal e/ou cúbica), causadas por aquecimento ou resfriamento da zircônia, faz-se necessária uma estabilização, que pode ser realizada a partir de dopagem com determinados elementos químicos, tais como: $\mathrm{Mg}, \mathrm{Ca}, \mathrm{Y}, \mathrm{Ce}$, que se incorporam efetivamente na estrutura da zircônia. A estabilização ocorre devido à substituição de átomos de zircônio pelos elementos dopantes, através da formação de vacâncias, onde ocorre a estabilização da zircônia $[12,13,14]$.

Ao dopar a zircônia com pequenas quantidades de óxido de ítrio $\left(\mathrm{Y}_{2} \mathrm{O}_{3}\right)$, ocorrerá a estabilização da estrutura cristalina tetragonal da zircônia gerando um composto formado de grãos cristalizados na estrutura tetragonal metaestável, conhecida como zircônia tetragonal policristalina (Y-TZP). Em temperatura ambiente a estrutura da zircônia pura é monoclínica e a tetragonal existe apenas em temperaturas entre $1170{ }^{\circ} \mathrm{C}$ à $2370{ }^{\circ} \mathrm{C}$, após essa faixa de temperatura a estrutura existente é a cúbica [15].

Ao sofrer uma determinada pressão, a cerâmica Y-TZP à temperatura ambiente pode transformar sua fase em monoclínica, gerando aumento no seu volume em torno de $4 \%$ a $5 \%$ [16]. O mecanismo ficou conhecido como "tenacificação por transformação", sendo o grande responsável pelas notáveis propriedades mecânicas dessa cerâmica [17].

Apesar de todas as vantagens citadas anteriormente acerca da zircônia, um problema recorrente neste tipo de material pode ser atribuído a sua coloração e aspecto óptico, uma vez que apresenta-se opaca e sua coloração branca não consegue mimetizar de forma adequada o tom natural dos dentes, além da sua difícil reprodutibilidade referente a coloração artificial, o que diminui o conforto estético dos pacientes. Considerando-se os recobrimentos existentes no mercado, os mesmos não apresentam grande durabilidade e nem qualidade estética, principalmente no que diz respeito aos dentes frontais [18].

Atualmente são utilizadas técnicas de moagem para pigmentar a zircônia, o que pode provocar diversas alterações e não garante a nuance de cores homogêneas, já que a mistura ocorre fisicamente [19]. A utilização de métodos adequados para a síntese de pós cerâmicos é de grande relevância, pois as qualidades em uma cerâmica dependem, em grande parte, das características originais dos pós utilizados. O método Pechini, destaca-se por sua variabilidade na síntese de pós cerâmicos. Esse processo permite uma maior precisão estequiométrica, uniformidade na mistura dos componentes, maior homogeneidade, baixo custo e não necessita de aparelhagem sofisticada para sua síntese [12, 20, 21].

Além da adição de óxido de ítrio para estabilização, tem surgido a necessidade de se agregar outros elementos químicos à zircônia para gerar um produto pigmentado. A alteração da cor dos pós a base de zircônia é feita pela adição de outros óxidos no momento da sintetização dos pós de zircônia, como por exemplo: $\mathrm{Fe}_{2} \mathrm{O}_{3}, \mathrm{ZnO}, \mathrm{Cr}_{2} \mathrm{O}_{3}, \mathrm{Al}_{2} \mathrm{O}_{3}$, etc. Diante disto, o presente trabalho visa desenvolver zircônia pigmentada com diversas nuances de cores utilizando como agente pigmentante o óxido de ferro $\left(\mathrm{Fe}_{2} \mathrm{O}_{3}\right)$ via método Pechini. As pequenas concentrações adicionadas podem alterar significativamente a tonalidade final da prótese de zircônia. Além disso, serão avaliados o potencial citotóxico dessas amostras e os demais componentes em células humanas, investigando qual composto será mais adequado para o uso na odontologia.

\section{MATERIAIS E MÉTODOS}

Para a produção dos pós de zircônia pigmentada via método Pechini, foram utilizadas variadas concentrações de agente pigmentante $\left(\mathrm{Fe}_{2} \mathrm{O}_{3}-3 \%, 2 \%, 1 \%, 0,5 \%\right.$ e 0,25 \% em mol), nomeadas como $\mathrm{FZ}_{3}, \mathrm{FZ}_{2}, \mathrm{FZ}_{1}$, 
$\mathrm{FZ}_{0,5}$ e $\mathrm{FZ}_{0,25}$, respectivamente, além destes tem o $\mathrm{FZ}_{0}$ que representa a amostra pura, sem adição de ferro. Os materiais utilizados na síntese foram oxinitrato de zircônio - $\mathrm{ZrO}\left(\mathrm{NO}_{3}\right)_{2}$, (Aldrich, $99 \%$ de pureza, hidradato), cloreto de ítrio- $\mathrm{YCL}_{3} .6 \mathrm{H}_{2} \mathrm{O}$ (Aldrich, $99 \%$ de pureza), nitrato de ferro-Fe $\left(\mathrm{NO}_{3}\right)_{3} .9 \mathrm{H}_{2} \mathrm{O}$ (Aldrich, $99 \%$ de pureza), ácido cítrico- $\mathrm{C}_{6} \mathrm{H}_{8} \mathrm{O}_{7}$ (Vetec, 99,5 \% de pureza), hidróxido de amônio - $\mathrm{NH}_{4} \mathrm{OH}$ (Aldrich, $99 \%$ de pureza), etileno glicol- $\left.\mathrm{C}_{2} \mathrm{H}_{4}(\mathrm{OH})_{2}\right)$ (Synth, $99 \%$ de pureza) e água destilada.

Inicialmente foi preparada uma solução em um Becker, utilizando $80 \mathrm{~mL}$ de água destilada e ácido cítrico (agente complexante) $\left(202 \mathrm{~g}\right.$ ), onde a solução foi agitada por 15 minutos a uma temperatura de $70{ }^{\circ} \mathrm{C}$. A seguir, foram adicionados o oxinitrato de zircônio $\left(\mathrm{ZrO}-\left(\mathrm{NO}_{3}\right)_{2}\right)(231,23 \mathrm{~g} / \mathrm{mol})$, onde dependendo da homogeneidade da solução e transcorrido o tempo adicionou-se o cloreto de ítrio $\left(\mathrm{YCl}_{3} \cdot 6 \mathrm{H}_{2} 0\right)(195,26 \mathrm{~g} / \mathrm{mol})$, sendo $3 \mathrm{~mol} \%$ de $\mathrm{Y}_{2} \mathrm{O}_{3}$, em seguida foi adicionado nitrato de ferro para pigmentar a amostra. Após esse processo, adicionou-se o hidróxido de amônio $(25 \mathrm{~mL})$ para se ajustar ao $\mathrm{pH} 8$ e, finalmente, o etileno glicol (25 $\mathrm{mL}$ ) para formar a resina polimérica. Após as adições dos reagentes a solução foi submetida a uma temperatura de $85{ }^{\circ} \mathrm{C}$ durante 4 horas, ocasionando a redução do volume da solução, onde a resina apresentou uma cor escura. A resina foi pirolisada a $350{ }^{\circ} \mathrm{C}$ por $2 \mathrm{~h}$ para formação do "puff". Posteriormente o pó foi calcinado a $1000{ }^{\circ} \mathrm{C}$, com uma taxa de aquecimento de $10^{\circ} \mathrm{C} / \mathrm{min}$, durante $4 \mathrm{~h}$ para todas as composições.

Para a análise e identificação das estruturas cristalinas nas amostras de $\mathrm{ZrO}_{2}$ pigmentadas com $\mathrm{Fe}_{2} \mathrm{O}_{3}$, foi utilizado o difratômetro de raios-X (DRX) Shimadzu XRD-6000, radiação de CuK $\alpha(\lambda=1,5418 \AA$ ). Foi utilizado o microscópio eletrônico de varredura com fonte de elétrons por emissão de campo (MEV), da marca FEI e modelo Quanta FEG 250, com tensão de aceleração de $30 \mathrm{kV}$, equipado com EDS de SDD, que conta com uma resolução de $126 \mathrm{eV}$ e detector Apollo X SDD, marca Ametek, modelo HX-1001, com deposição de ouro.

Os valores numéricos de cores das amostras de zircônia, foram obtidos utilizando-se o espectrofotômetro de reflexão (CM-2600D, Konica Minolta Sensing Inc), com a realização da medição de acordo com a CIE 1976.

Para o teste de toxicidade utilizou-se a Artemia salina, tipo de crustáceo marinho, organismo simples, que pode ser utilizado para determinar a letalidade de algum composto. O parâmetro utilizado é apenas a morte ou vida dos crustáceos ao entrarem em contato com o composto, gerando uma resposta rápida e simples, permitindo conhecer a toxicidade geral do material [22].

As amostras de zircônia dopadas com ferro foram preparadas em triplicatas a uma concentração de 10 $\mathrm{mg} / \mathrm{mL}(10.000 \mu \mathrm{g} / \mathrm{mL})$, utilizando um veículo extrator para inseri-las em frascos (tubos de ensaio ou eppendorfs), para o ensaio de citotoxicidade. Depois disso as amostras foram incubadas durante $24 \mathrm{~h}$ à temperatura de $37^{\circ} \mathrm{C}$, sob agitação leve [23]. Após a incubação ocorreu a sedimentação do material e em seguida a centrifugação das amostras. Posteriormente foram realizadas as diluições das amostras a partir do sobrenadante, para obtenção de determinadas concentrações utilizando o veículo extrator como solvente, as concentrações utilizadas foram: $10 \mathrm{mg} / \mathrm{mL}, 5 \mathrm{mg} / \mathrm{mL}, 1 \mathrm{mg} / \mathrm{mL}, 0,5 \mathrm{mg} / \mathrm{mL}$ e $0,1 \mathrm{mg} / \mathrm{mL}$.

Com as amostras preparadas para a realização do teste de toxicidade aguda [24], foi realizada a manipulação dos ovos de Artemias salina para sua futura eclosão. Adicionou-se cerca de $50 \mathrm{mg}$ de ovos do crustáceo em cerca de $1 \mathrm{~L}$ de água do mar sintética (previamente preparada), com iluminação artificial (lâmpada) e oxigenação (bomba de aquário) por 24 h a 48 h [25, 24]. Após a eclosão dos ovos, foram separados 10 naúplios (com adequada movimentação) para cada tubo de ensaio (cada tubo para uma concentração), onde os tubos de ensaio continham $9 \mathrm{~mL}$ de água do mar sintética. Depois foi adicionado $1 \mathrm{~mL}$ da concentração teste (amostra) para cada tubo, resultando ao final $10 \mathrm{~mL}$ (água do mar mais a amostra). Após a incubação dos tubos por $24 \mathrm{~h}$, contaram-se os números de naúplios (artêmias) vivos com auxilio de lupa e registrou a quantidade, depois de $48 \mathrm{~h}$ houve uma coleta de dados, a fim de calcular a toxicidade do material estudado.

\section{RESULTADOS E DISCUSSÃO}

Os difratogramas dos pós de zircônia sintetizados pelo método Pechini, em diferentes concentrações de ferro $(3 \%, 2 \%, 1 \%, 0,5 \%, 0,25 \% \mathrm{em} \mathrm{mol})$ comparativamente à amostra pura $\left(\mathrm{FZ}_{0}\right)$, são mostrados na Figura 1. 


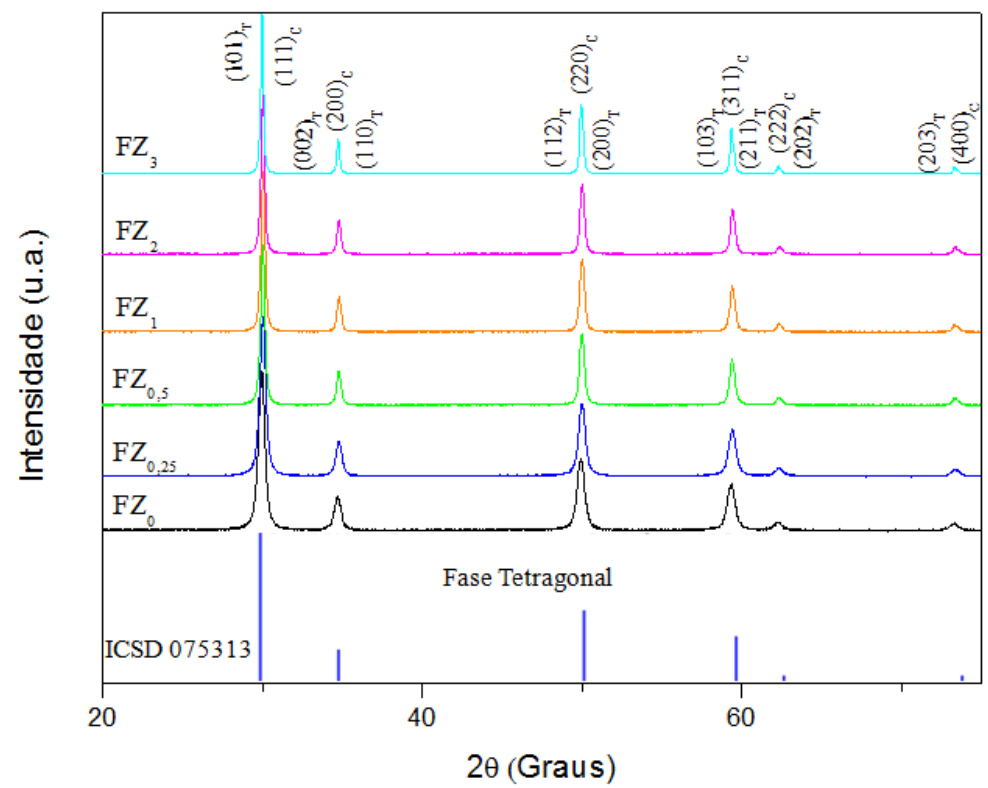

Figura 1: Difratogramas das amostras de zircônia pigmentada com óxido de ferro nas concentrações $0,25 \%$, $0,5 \%, 1 \%, 2 \%, 3 \%$ e estabilizada com ítrio a 3\% e zircônia pura (sem pigmentação), calcinados à temperatura de $1000{ }^{\circ} \mathrm{C}$.

De acordo com o difratograma (Figura 1) os picos que apresentam maior intensidade estão relacionados aos planos cristalográficos (111), (220) e (311). De acordo com a análise da literatura e a partir do banco de dados como o Inorganic Crystal Structure Database (ICSD 60393), foi possível identificar a fase cúbica como majoritária no material em estudo. Verificou-se também, que o aumento na proporção do agente pigmentante $\left(\mathrm{Fe}_{2} \mathrm{O}_{3}\right)$ promoveu a diminuição no alargamento dos picos (111), (200), (220) e (311), devido à efetiva inserção do elemento dentro da rede cristalina, propiciando o rearranjo atômico e consequentemente o aumento da cristalinidade.

Analisando os padrões de DRX ilustrados na Figura 1, identifica-se que todos os picos existentes podem ser caracterizados como pertencentes a uma estrutura cúbica de face centrada e estrutura tetragonal. No entanto devido aos planos de fase cúbica $(111,200,220$ e 311) estarem sobrepondo os planos de fase tetragonal cristalina $(101,110,112,200,103)$, há dificuldade na identificação desta microestrutura, onde os parâmetros de rede "a" são muito parecidos e simétricos para as estruturas em tetragonais (ICSD 075313), com a=0,5094 $\mathrm{nm}$ para tetragonal e a=0,5124 $\mathrm{nm}$ para cúbica, uma diferença de apenas 0,003 nm [26].

A Figura 2a, mostra que a dopagem com íons $\mathrm{Fe}^{3+}$ na rede $\mathrm{Y}_{2} \mathrm{O}_{3}-\mathrm{ZrO}_{2}$ promove pequenos deslocamentos para a direita de todos os picos de difração para valores de ângulos maiores. De acordo com a lei de Bragg $(\mathrm{n} \lambda=2 \mathrm{~d} \operatorname{sen} \theta)$, esse deslocamento dos ângulos $2 \theta$ ocorre quando há uma mudança nos parâmetros da rede de célula unitária [27]. Além disso, é possível afirmar que o espaçamento da partícula é inversamente proporcional ao ângulo de espalhamento, estando de acordo com o comportamento dos picos [28].

Esse comportamento é atribuído à introdução de íons $\mathrm{Fe}^{3+}$ nos sítios atômicos, que possuem um raio iônico de $0,64 \AA$, sendo menor do que o raio iônico do zircônio $(0,72 \AA)$, indicando que a dopagem do material promove uma diminuição do volume de célula unitária. 

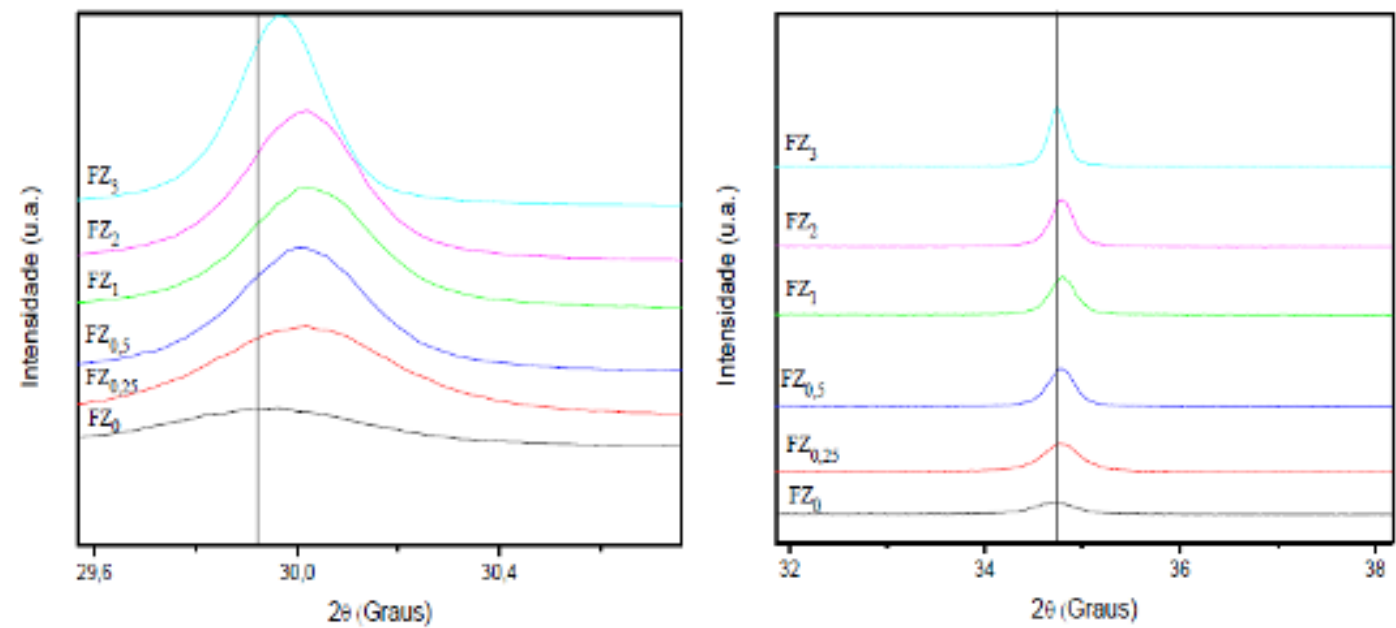

Figura 2: (a) e (b) Padrões de DRX correspondente aos planos (111) e (200) indicando o deslocamento lateral observado para as amostras estudadas.

A Figura 3 apresenta os tamanhos médios de cristalitos, com medidas que aumentam proporcionalmente com a concentração de ferro, indicando a variação dos tamanhos de cristalitos de zircônia dopada em relação à zircônia pura $(35,45 \mathrm{~nm})$. Para as amostras em estudo também se verificou que com a alta temperatura, durante a calcinação, ocorre um aumento no tamanho médio dos cristalitos e da diminuição dos parâmetros de rede [29]. O crescimento do tamanho médio dos cristalitos ocorre devido à energia térmica do sistema, promovendo sua coalescência [30]. Durante o processo, os cristalitos menores unem-se entre si formando partículas maiores, ou seja, com menor área superficial e são termodinamicamente mais estáveis, resultando na diminuição das distâncias interplanares e consequentemente seus parâmetros de rede [31].

Os diâmetros dos cristalitos foram determinados pela fórmula de Scherrer, com o auxílio do software HighScore Plus versão 3.0d (304) 2011 da PANalytical, que forneceu os valores dos ângulos de Bragg e FWHM (largura a meia altura do pico de difração da amostra) para a realização do cálculo, além de permitir a análise qualitativa das fases presentes em cada amostra [32, 33].

Tamanho médio de cristalitos (mm)

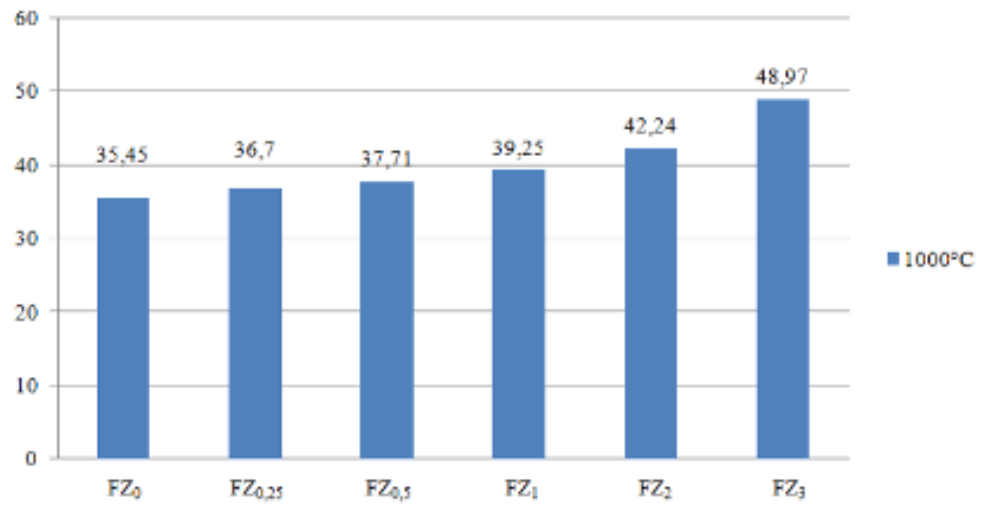

Figura 3: Tamanho médio de cristalitos de zircônia dopada com variadas concentrações de ferro.

A Figura 4 apresenta um gráfico referente aos valores de parâmetros de rede (a) calculados para todas as amostras de zircônia. Os parâmetros de rede foram obtidos através de refinamento Rietveld e os dados cristalográficos das fases presentes necessários para realizar o método foram obtidos através das fichas cristalográficas CIF's [34]. A partir do histograma apresentado na Figura 4 é possível observar a diminuição dos valores de parâmetros de rede para os pós de zircônia à medida que o teor de ferro aumenta, comprovando que houve de forma efetiva a dopagem do material, onde o agente pigmentante foi inserido na estrutura da rede cristalina da zircônia, obtendo-se dessa forma um material monofásico o que é de fundamental importância para não alterar as propriedades do material estudado, corroborando assim com os resultados apresentados na Figura 1. No entanto, não houve grandes variações nas amostras sintetizadas, com exceção da $\mathrm{FZ}_{2} \mathrm{e}$ 
$\mathrm{FZ}_{3}$, já que os mesmos apresentaram resultados distintos dos parâmetros de rede, quando comparados com a zircônia pura e demais amostras, com uma diferença de 0,5142 e 0,8016 respectivamente, referente à inserção do agente pigmentante no material.

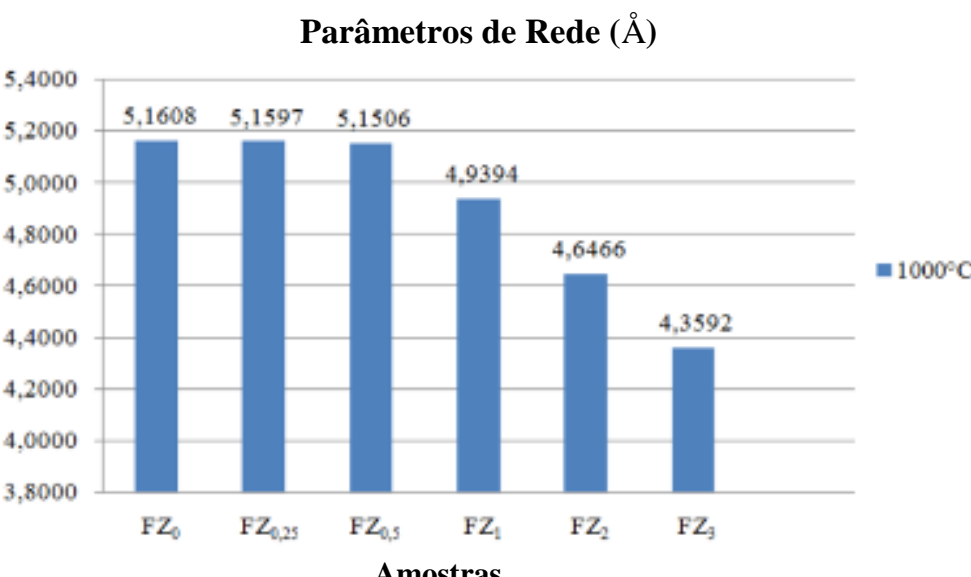

Figura 4: Parâmetros de rede das amostras de zircônia dopadas com ferro.

A Figura 5 apresenta as micrografias da zircônia em diferentes concentrações (a-FZ, b-FZ 2 , c-FZ, $\mathrm{d}-\mathrm{FZ}_{0,5}$, e-FZ $\mathrm{FZ}_{0,2}$ ) calcinadas a temperatura de $1000{ }^{\circ} \mathrm{C}$. A morfologia das amostras estudadas possui comportamento similar aos de materiais obtidos via método Pechini, com aparência de flakes ou espumas, que são oriundas do aprisionamento de gases formados durante a produção do gel, além disso, apresentam morfologia irregular e baixa adesão entre as partículas, sendo facilmente desaglomeradas. Verificou-se ainda que o aumento na concentração de ferro não interferiu na morfologia final do material e nem em seu tamanho [35].
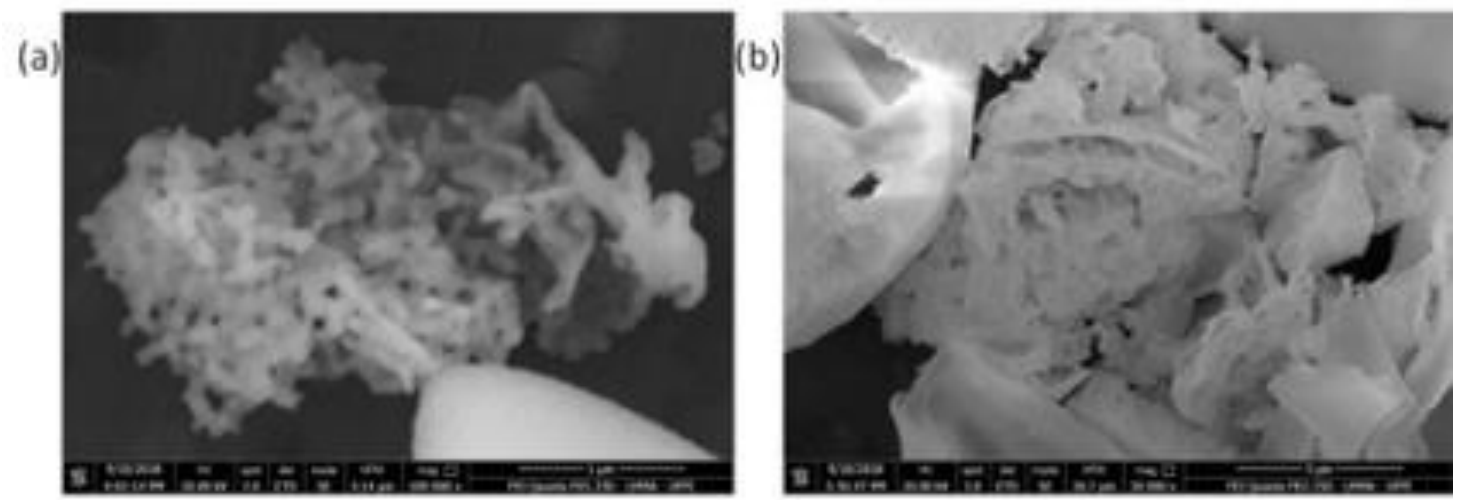

(c)
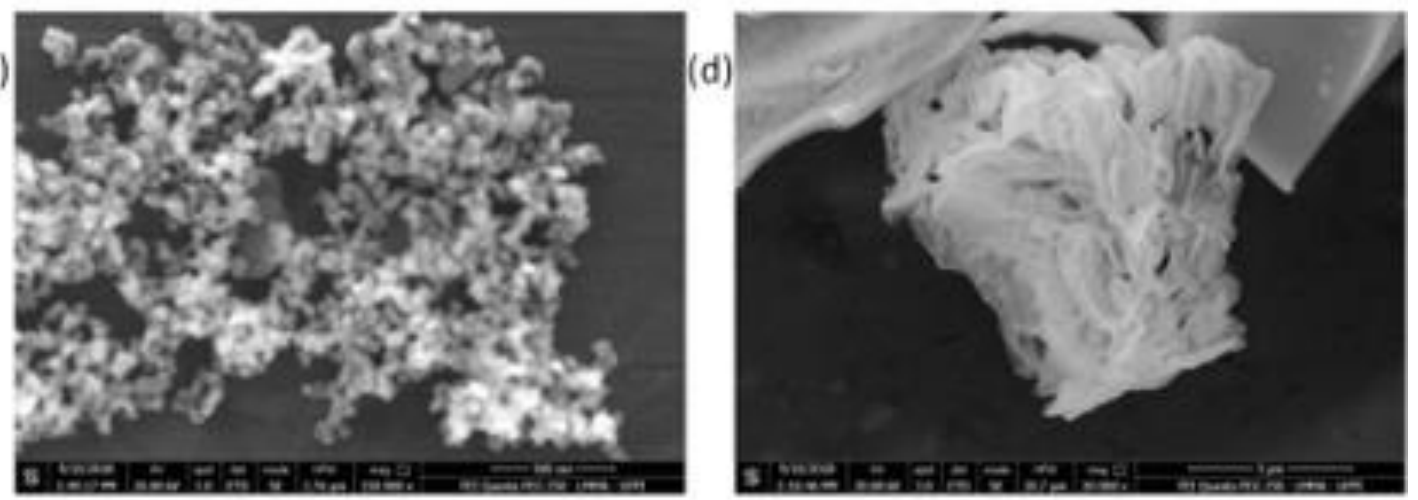


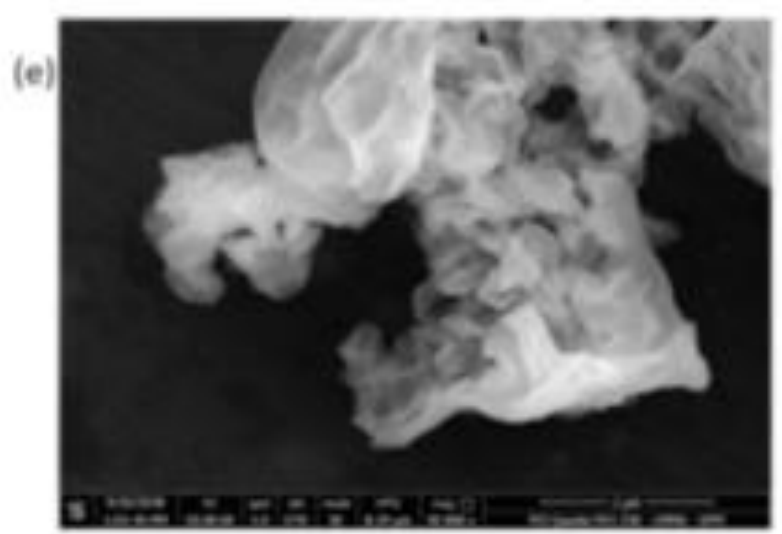

Figura 5: Micrografias das amostras de zircônia: a $\left(\mathrm{FZ}_{3}\right), \mathrm{b}\left(\mathrm{FZ}_{2}\right), \mathrm{c}\left(\mathrm{FZ}_{1}\right), \mathrm{d}\left(\mathrm{FZ}_{0,5}\right)$ e $\left(\mathrm{FZ}_{0,25}\right)$.

A Figura 6 apresenta os resultados referentes à espectroscopia de energia dispersiva (EDS), indicando os elementos presentes nas amostras estudadas.
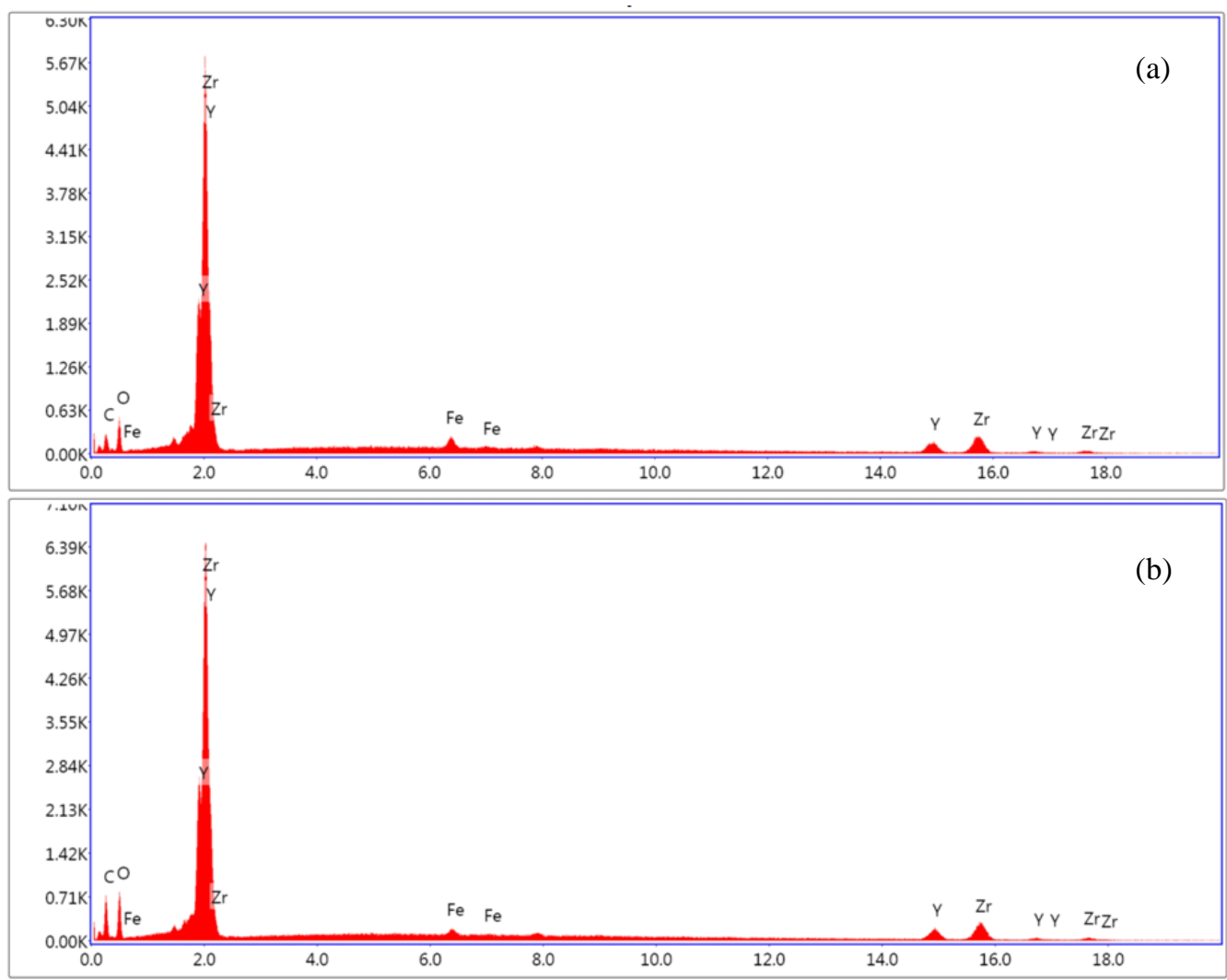

Lsec: $100.0 \quad 107$ Cnts $8.010 \mathrm{keV}$ Det:Apollo X-SDD Det

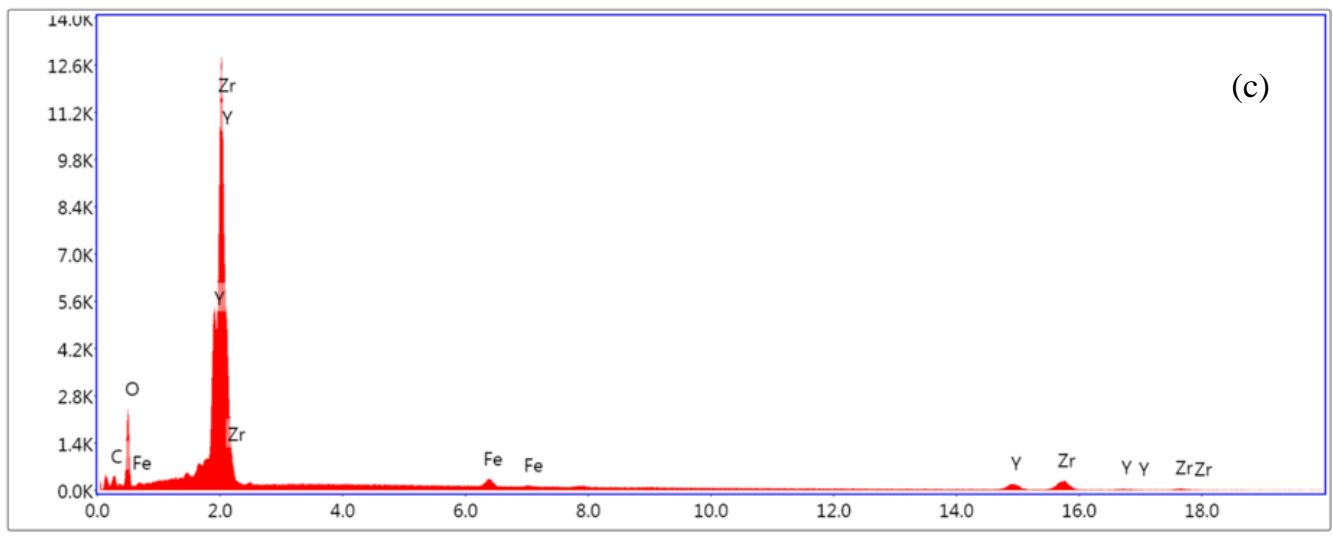

Lsec: $100.0 \quad 112$ Cnts $8.010 \mathrm{keV}$ Det:Apollo X-SDD Det 


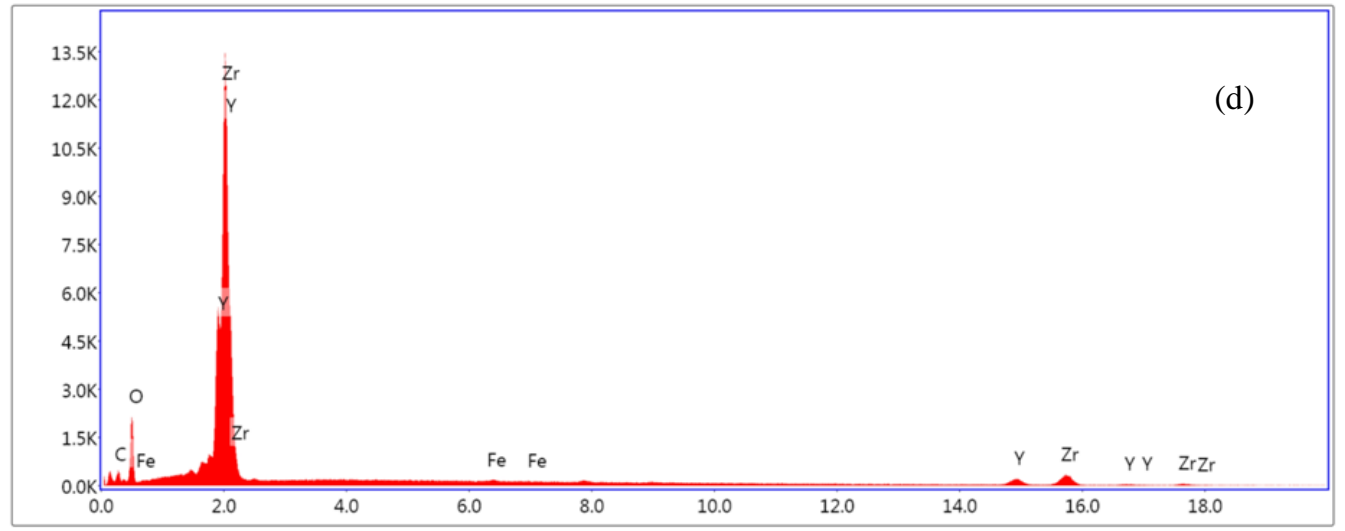

Lsec: $100.0 \quad 110$ Cnts $8.010 \mathrm{keV} \quad$ Det: Apollo X-SDD Det

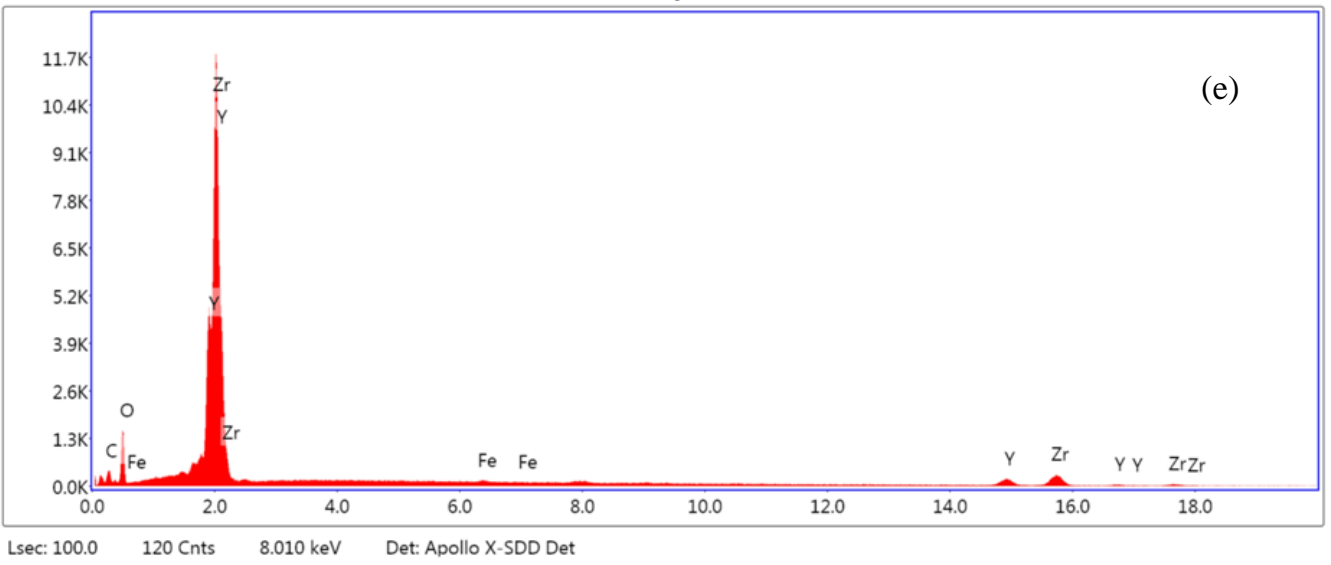

Figura 6: Espectros de EDS para as amostras (a) $\mathrm{FZ}_{3}$; (b) $\mathrm{FZ}_{2}$; (c) $\mathrm{FZ}_{1}$; (d) $\mathrm{FZ}_{0.5}$; (e) $\mathrm{FZ}_{0.25}$.

Os picos localizados nas posições: $2.0 ; 15.0 ; 0.5 ; 6.5 ; 0.3 \mathrm{KeV}$, respectivamente, confirmam a presença dos elementos zircônio, ítrio, oxigênio, ferro e carbono para todas as amostras analisadas por EDS, no qual foram feita análises em três pontos distintos de cada amostra. A presença do pico de carbono embora não faça parte da estequiometria original do material em estudo, pode ser atribuída à fita de fixação das amostras durante o ensaio, fazendo com que haja a presença desse pico durante a análise do EDS, pois não há como diferenciar o que é amostra ou porta amostra durante a realização da análise da composição por energia dispersiva de raios $\mathrm{X}$.

As análises de toxicidade das amostras de zircônia com variadas proporções de ferro (3\%; $2 \%$; $1 \% ; 0,5 \% ; 0,25 \%$ em mol), , realizadas com Artemia salina foram realizadas para os tempos de 24 e $48 \mathrm{~h}$ de exposição, e avaliados o seu potencial de acordo com a Figura 7.

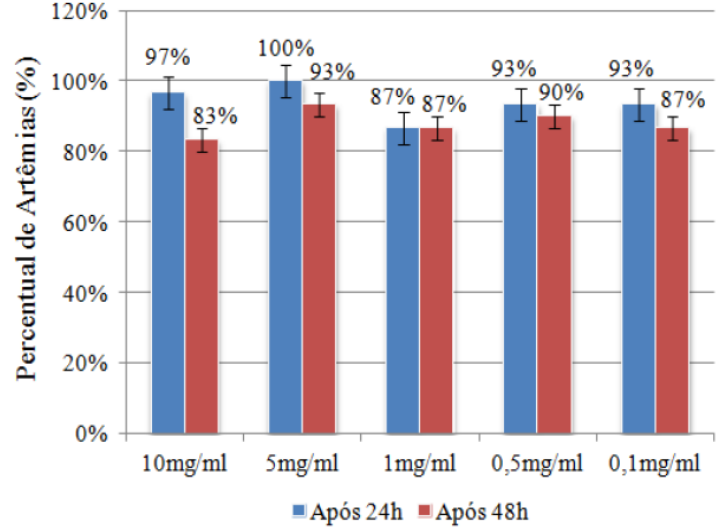

$\mathrm{FZ}_{3}$

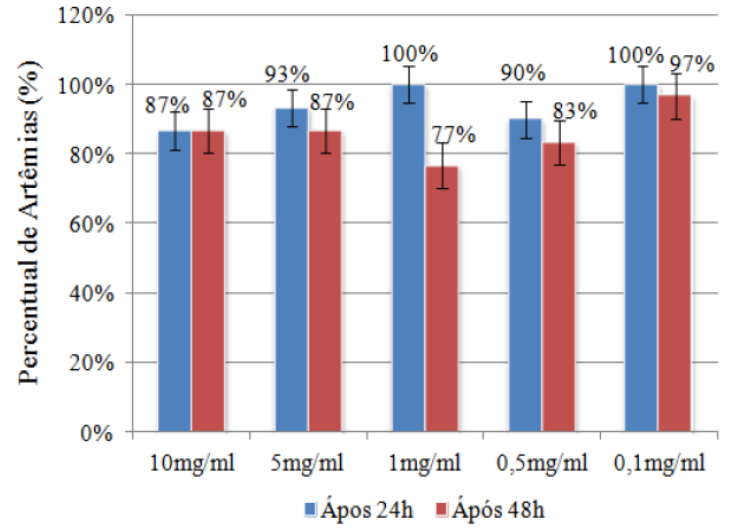

$\mathrm{FZ}_{2}$ 

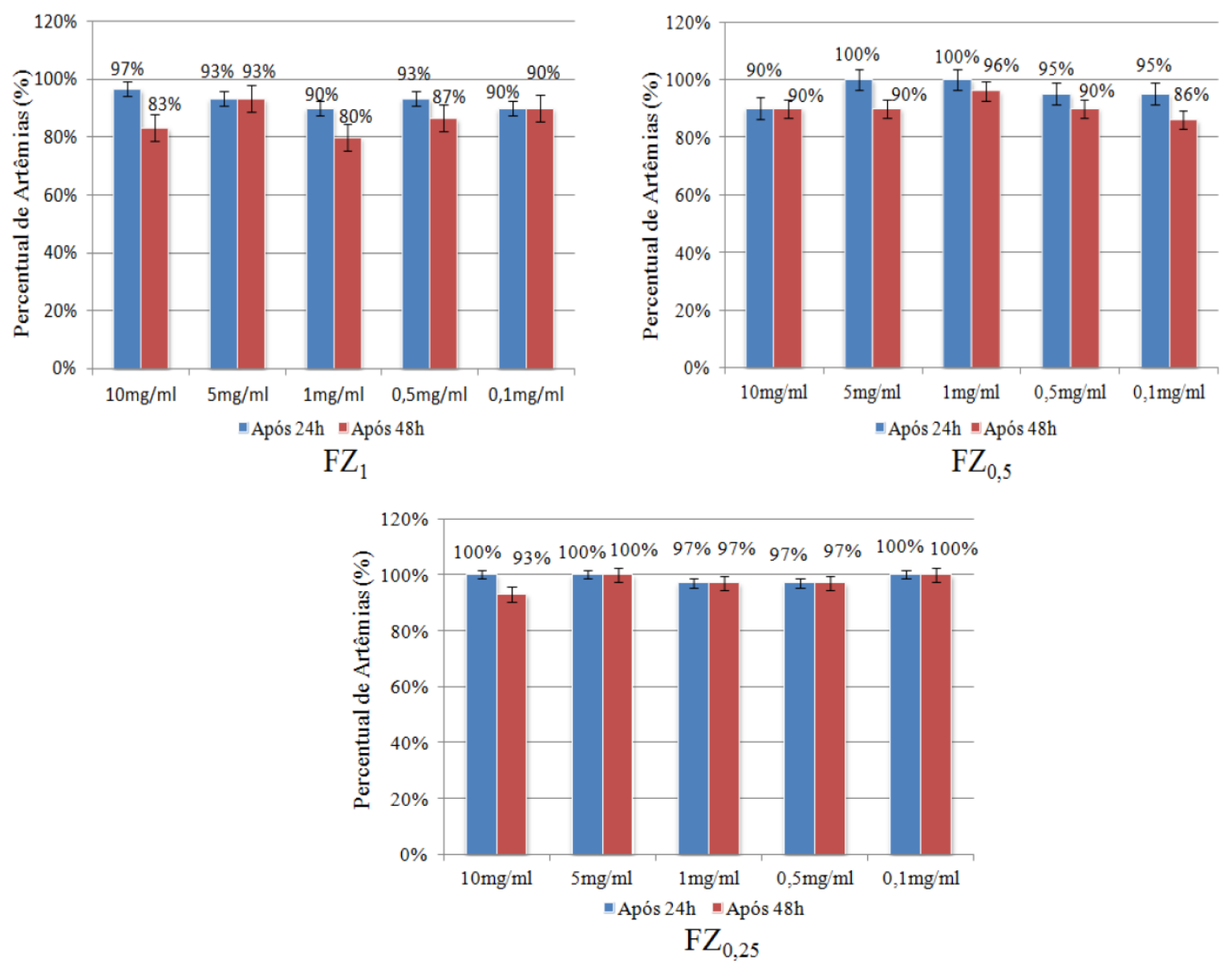

Figura 7: Análise de toxicidade dos pós de zircônia dopados com variadas concentrações de ferro $\left(\mathrm{FZ}_{3} ; \mathrm{FZ}_{2} ; \mathrm{FZ}_{1} ; \mathrm{FZ}_{0.5}\right.$; $\mathrm{FZ}_{0,25}$ ).

Para os gráficos das amostras $\mathrm{FZ}_{3}, \mathrm{FZ}_{0,5}$ e $\mathrm{FZ}_{0,25}$, as concentrações de Artemias que apresentaram maior disparidade foram as de $10 \mathrm{mg} / \mathrm{mL}$, com valores variando de $14 \%, 14 \%$ e $7 \%$ respectivamente, para os intervalos de tempo de $24 \mathrm{~h}$ e $48 \mathrm{~h}$. Já para as amostras $\mathrm{FZ}_{2}$ e $\mathrm{FZ}_{1}$ as concentrações com maiores disparidades foram as de $1 \mathrm{mg} / \mathrm{mL}$ e $5 \mathrm{mg} / \mathrm{mL}$, apresentando valores de $2 \%$ e $4 \%$, respectivamente. Comparativamente, analisou-se que o desvio padrão das amostras apresentou resultados inferiores paras as amostras $\mathrm{FZ}_{3}$, $\mathrm{FZ}_{2}, \mathrm{FZ}_{1}, \mathrm{FZ}_{0,5}$ e $\mathrm{FZ}_{0,25}$, mostrando que os resultados tem um alto nível de confiabilidade. $\mathrm{O}$ teste de toxicidade feito com Artemia salina é um ensaio biológico bastante usado para uma avaliação preliminar de toxicidade para compostos com atividade biológica [36, 25, 22]. Todas as soluções testadas de zircônia mostraram baixa toxicidade (Figura 7), com quantidade de naúplios vivos acima de $60 \%$ em todas as concentrações, para um tempo de observação entre 24 e 48 h. Não houve uma diferença significativa com relação ao número de Artemias salina vivas entre $24 \mathrm{~h}$ e $48 \mathrm{~h}$, o que indica que a toxicidade é nula.

A análise colorimétrica é um procedimento imprescindível para avaliar o material em estudo, pois a partir desta foi possível quantificar as cores através de números e escolher a concentração mais adequada para o uso odontológico. O parâmetro $\mathrm{L}^{*}$ é referente ao brilho do material, o $\mathrm{a}^{*}$ está relacionado à cor vermelha (positivo) / verde (negativo) e o b* está relacionado às cores amarelo (positivo)/ azul (negativo) [37, 38]. A Tabela 1 apresenta os valores das escalas de cores para as amostras de zircônia.

Tabela 1: Escalas de cores das amostras de zircônia dopadas com ferro.

\begin{tabular}{c|c|c|c}
\hline AMOSTRAS & $\mathbf{L}^{*}$ & $\mathbf{a}^{\boldsymbol{*}}$ & $\mathbf{b}^{\boldsymbol{*}}$ \\
\hline $\mathrm{FZ}$ & 73,78 & 8,49 & 12,27 \\
\hline $\mathrm{FZ}_{2}$ & 79,57 & 6,77 & 23,42 \\
\hline $\mathrm{FZ}_{1}$ & 88,35 & 2,82 & 15,82 \\
\hline $\mathrm{FZ}_{0,5}$ & 91,56 & 1,47 & 10,83 \\
\hline $\mathrm{FZ}_{0,25}$ & 94,55 & 0,35 & 6,41 \\
\hline
\end{tabular}


A partir da Tabela 1, é possível observar que as amostras $\mathrm{FZ}_{0,25}$ e $\mathrm{FZ}_{0,5}$ são as que possuem maior brilho de acordo com o parâmetro $\left(\mathrm{L}^{*}\right)$, porém esses valores estão acima da média estipulada pelas coordenadas de cores CIELAB L*=59,9-84,1, não sendo dessa forma indicadas para odontologia. Para o parâmetro $\left(\mathrm{a}^{*}\right)$, os valores obtidos estão próximos de zero em relação as amostras $\mathrm{FZ}_{0,25}$ e $\mathrm{FZ}_{0,5}$, indicando que a coloração dos pós de zircônia possuem coloração branca. Em consonância com o parâmetro (a*), o parâmetro (b*) apresenta uma tonalidade levemente amarela o que pode ser confirmado na referida tabela já que os valores se distanciam de zero, com esses valores de $\mathrm{a}^{*} \mathrm{e} \mathrm{b}^{*}$ estando próximo dos valores relatados pela CIELab, $\mathrm{a}^{*}=1,9-8,1$ e $\mathrm{b}^{*}=7.4-14,6[39,40]$. A amostra $\mathrm{FZ}_{1}$ apresenta valores de escalas $\mathrm{a}^{*}$ e $\mathrm{b}^{*}$ aceitáveis, porém o valor de brilho L*, se distanciou um pouco dos padrões CIELab*, entretanto é o material com concentração de ferro, que mais se aproxima. As amostras $\mathrm{FZ}_{2}$ e $\mathrm{FZ}_{3}$ são as que possuem menor brilho, não servindo para aplicações odontológicas, além disso, suas escalas indicam níveis de vermelhidão medianos ( $\left.\mathrm{a}^{*}\right)$ e uma forte tonalidade amarela $\left(b^{*}\right)$. Porém é necessário também ver os pós de zircônia coloridos a olho nu, complementando os dados obtidos pelo espectrofotômetro, para avaliar qual deles irá se assemelhar melhor à dentina humana.

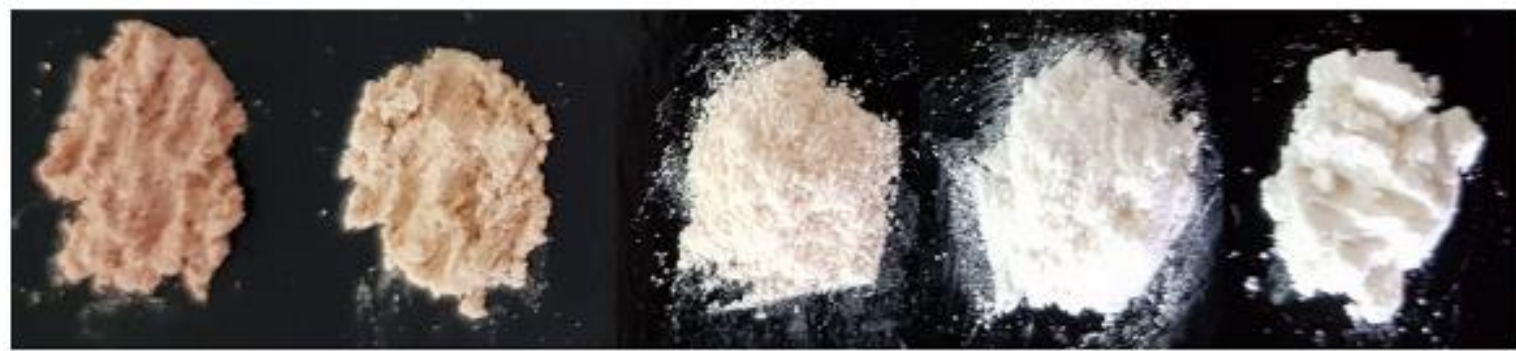

Figura 8: amostras de zircônia pigmentadas com proporções de ferro de forma decrescente $\left(\mathrm{FZ}_{3} ; \mathrm{FZ}_{2} ; \mathrm{FZ}_{1} ; \mathrm{FZ}_{0,5} ; \mathrm{FZ}_{0,25}\right)$.

Por meio da Figura 8, pode-se confirmar a análise pelo CIELab e os pós obtidos durante a síntese da zircônia, dentre as nuances de cores obtidos, os que mais se assemelham à tonalidade da dentição humana são $\mathrm{FZ}_{1} ; \mathrm{FZ}_{0,5}$ e $\mathrm{FZ}_{0,25}$, respectivamente. Dentro desse contexto, observa-se que o pó referente à amostra $\mathrm{FZ}_{1}$ é, o que mais se aproxima da dentina humana, sem gerar uma aparência artificial para aplicações odontológicas em restaurações, sendo de fundamental importância para garantir o conforto do paciente, aliando a funcionalidade deste material ao aspecto estético.

Para a odontologia já existe um sistema padrão para medir e determinar a tonalidade dos dentes, através de colorímetros comerciais de uso odontológico, além dos guias de tonalidades para auxiliar na escolha que mais se adequa aos dentes de cada ser humano, como pode ser visto na Figura 9.

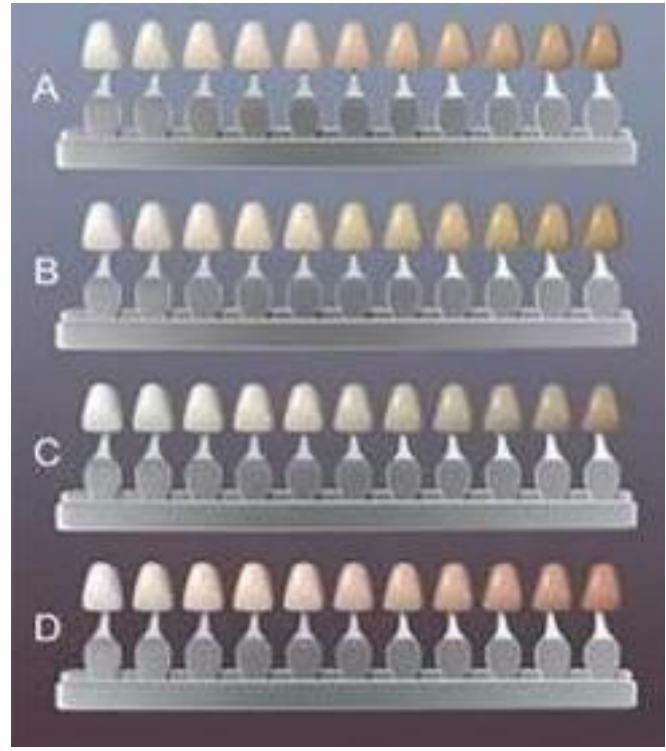

Figura 9: Guia de tonalidades para os dentes [41]. 
O guia divide a tonalidade dos dentes em quatro tons básicos: A (marrom avermelhado), B (amarelo avermelhado), C (acinzentado) e D (cinza avermelhado). Para cada graduação existem vários níveis de escurecimento, de forma que atenda todas as variações de cor da dentina humana. Para os pós de zircônia da Figura 9, o tom "A" é o que mais se aproxima deles.

\section{CONCLUSÕES}

A análise de DRX mostrou a presença das fases cúbicas e tetragonais como majoritárias. Verificou-se que o aumento no percentual de ferro causou uma diminuição gradativa da largura da base dos picos, quando comparadas à zircônia pura $\left(\mathrm{FZ}_{0}\right)$, além do deslocamento dos picos para a direita, indicando que o ferro entrou na rede cristalina ocupando os vazios e tornando o material mais cristalino.

Os parâmetros de rede da zircônia pura apresentam valores maiores quando comparadas às amostras com ferro devido a substituições na rede cristalina do zircônio por ferro e também devido à energia térmica gerada no processo de calcinação.

Para os tamanhos de cristalitos ocorre o inverso, com o aumento do teor de ferro observou-se um aumento no diâmetro dos cristalitos, pois a introdução de mais um íon dentro da estrutura aumenta seu fator de empacotamento e consequentemente, o tamanho dos cristalitos.

No MEV, observou-se que o material calcinado apresenta morfologia irregular, na forma de espumas. O EDS indica a presença de ferro na microestrutura do material em diferentes concentrações de acordo com as dopagens escolhidas.

As caracterizações comprovam que a pigmentação da zircônia com ferro foi realizada de forma eficaz, o que garante a mudança de tonalidade dos pós de zircônia. As amostras apresentaram tonalidades diferentes, como cores homogêneas, como já era esperado, de acordo com a quantidade de ferro, revelando que as amostras mais adequadas são a $\mathrm{FZ}_{1}$ e $\mathrm{FZ}_{0,5}$ como mostram os resultados CIELab, podendo ser utilizadas para aplicações odontológicas.

\section{AGRADECIMENTOS}

Os autores estão agradecidos por toda ajuda e suporte dado pelas instituições que tornaram possível esta pesquisa: UFPI, LIMAV e a CAPES.

\section{BIBLIOGRAFIA}

[1] SHIBAYAMA, R, TIOSSI, R., QUEIROZ, M. E., et al., "Reabilitação estética dos elementos anteriores utilizando o sistema IPS e-max", Revista Odontologica de Araçatuba, v. 37, n. 2, pp. 27-33, Ago. 2016.

[2] BARROS, S.H.M., "O uso da zircônia na prática odontológica reabilitadora”, Trabalho de Conclusão de Curso, Faculdade de Odontologia/UFRS, Porto Alegre, Brasil, 2016.

[3] CHIMANSKI, A., CESAR, P.F., YOSHIMURA, H.N., "Effects of glass chemistry on the optical properties of highly translucent alumina-glass biocomposites for dental restorations", Ceramics Internacional, v. 43, n. 16, pp. 13970-13977, Nov. 2017.

[4] CARAVACA, C. F., FLAMANT, Q., ANGLADA, M., et al., "Impact of sandblasting on the mechanical properties and aging resistance of alumina and zirconia based ceramics", Journal of the European Ceramic Society, v. 38, n. 3, pp. 915-925, Mar. 2018.

[5] LÓPEZ, A.M.L., POZO, P.P., MUELA, C.M., et al., "Maxillary sinus augmentation with bovine hydroxyapatite alone: A safe technique with predictable outcomes in patients with severe maxillary atrophy", $R e$ vista Española de Cirugía Oral y Maxilofacial , v. 37, n. 2, pp. 87-92, Jun. 2015.

[6] SCHERER, M.M., PROCHNOW, C., VENTURINI, A.B., et al., "Fatigue failure load of an adhesivelycemented lithium disilicate glassceramic: Conventional ceramic etching vs etch \& prime one-step primer", Dental Materials, v. 34, n. 8, pp. 1134-1143, Ago. 2018.

[7] QUINTERO, J.V.U., AYALA, A.H., PLATA, R.G., et al., "Tratamiento restaurador de lesiones dentales traumáticas. Reporte de tres casos clínicos”, Revista Odontológica Mexicana, v. 21, n. 3, pp. 185-197, Set. 2017.

[8] AMARANTE, J. E. V., PEREIRA, M. V. S., SOUZA, G. M., ALVES, M. F. R. P., SIMBA, B. G., SANTOS, C., "Roughness and its effects on flexural strength of dental yttria-stabilized zirconia ceramics", Materials Science and Engineering: A, v. 739, pp. 149-157, Jan. 2019. 
[9] ABORAS, M., MUCHTAR, A., AZHARI, C. H., YAHAYA, N., MAH, J. C. W., "Enhancement of the microstructural and mechanical properties of dental zirconia through combined optimized colloidal processing and cold isostatic pressing", Ceramics International, v. 45, n. 2, pp.1831-1836, Fev. 2019.

[10] KAVASHIMA, L. H., SANCHES, M. G., SOUSA, E. A. C., RAMOS, C. M., BORGES, A. F. S., FORTULAN, C. A., FOSCHINI, C., "Vickers microhardness analysis of pre-sintered Y-TZP zirconia for machining and subsequent application as copings", Revista Matéria, v. 22, n. 2, Jun. 2017.

[11] PARTIYAN, A., OSMAN, E., RAYYAN, M.M., ABOUSHELIB, M., IBRAHIM, A., JIMBO, R., "Fracture resistance of three-unit zirconia fixed partial denture with modified framework", Odontology, v. 105, n. 1, pp. 62-67, Jan. 2017.

[12] ANDRADE, I.M., "Síntese pelo método Pechini e caracterização da zircônia dopada com cério e neodímio", Tese de D.Sc., PPGQ/UFRN, Natal, RN, Brasil, 2012.

[13] ROITERO, E., LASSERRE, F., ANGLADA, M., et al., "A parametric study of laser interference surface patterning of dental zirconia: Effects of laser parameters on topography and surface quality", Dental Materials, v. 33, n. 1, pp. 28-38, Jan. 2017.

[14] SIVARAMAN, K., CHOPRA, A., NARAYAN, A., et al., "Is zirconia a viable alternative to titanium for oral implant? A critical review", Journal of Prosthodontic Research, v. 62, n. 2, pp. 121-133, 2018.

[15] KAVASHIMA, L.H., "Processamento e caracterização mecânica de cerâmica zircônia Y-TZP para manufatura de copings odontológicos", Tese M.Sc., UNESP, Bauru, SP, Brasil, 2016.

[16] LAMEIRA, D.P., "Fracture strength of monolithic and bi-layer zirconia-based crowns", Tese de D.Sc., UNICAMP, Piracicaba, SP, Brasil, 2014.

[17] EL-GHANY, O.S.A., SHERIEF, A.H., "Zirconia based ceramics, some clinical and biological aspects: Review”, Future Dental Journal, v. 2, n. 2, pp. 55-64, Dez. 2016.

[18] MENDES, P.F.C., ELIAS, C.N., DOS SANTOS, H.E.S., "Efeito da adição de $\mathrm{Fe}_{2} \mathrm{O}_{3}$ nas propriedades da zircônia estabilizada com ítria", Revista Matéria, v. 22, n. 2, Jun. 2017.

[19] LAN, T.H., WANG, C.H., CHEN, K.K., et al., "Grinding Properties of Low Temperature Sintered Zirconia Blocks for Dental Use”, Materials Science \& Engineering, v. 73, pp. 692-699, Abr. 2017.

[20] AFLAKI, M., DAVAR, F., "Synthesis, luminescence and photocatalyst properties of zirconia nanosheets by modified Pechini method", Journal of Molecular Liquids, v. 221, pp. 1071-1079, Set. 2016.

[21] NGUYEN, D.K., BACH, Q.V., KIM, B., et al., "Synthesis of Cr-doped $\mathrm{Al}_{2} \mathrm{O}_{3}$ by Pechini sol-gel method and its application for reversible thermochromic sensors", Materials Chemistry and Physics, v. 223, pp. 708714, Fev. 2019

[22] CAVALCANTE, M.F., OLIVEIRA, M.C.C., VELANDIA, J.R., et al., "Síntese de 1, 3, 5-triazinas substituídas e avaliação da toxicidade frente a Artemia salina leach", Química nova, v. 23, n. 1, pp. 20-22, Jun. 2000.

[23] NGUTA, J.M., MBARIA, J.M., GAKUYA, D.W., et al., "Biological screening of Kenyan medicinal plants using Artemia salina (Artemiidae)”, Pharmacologyonline, v. 2, pp. 458-478, 2011.

[24] MEYER, B.N., FERRIGNI, N.R., PUTNAM, J.R., et al., "Brine Shrimp: A convenient general bioassay for active plant constituents", Journal of Medicinal Plant Research, v. 45, pp. 31-34, Jan. 1982.

[25] NASCIMENTO, J.E., MELO, A.F.M., SILVA, T.C.L., et al., "Estudo fitoquímico e bioensaio toxicológico frente a larvas de Artemia Salina Leach. de três espécies medicinais do gênero Phyllanthus (Phyllanthaceae)", Revista de Ciências Farmacêuticas Básica e Aplicada, v. 29, n. 2, pp. 145-150, 2009.

[26] DAVAR, F., SHAYAN, N., "Preparation of zirconia-magnesia nanocomposite powders and coating by a sucrose mediated sol-gel method and investigation of its corrosion behavior", Ceramics International, v. 43, n. 3, pp. 3384-3392, Fev. 2017.

[27] MARCOS, P.J.B.; GOUVÊA, D., "Effect of MgO segregation and solubilization on the morphology of ZrO2 powders during synthesis by the Pechini's method", Cerâmica, v. 50, n. 313, pp. 38-42, Mar. 2004.

[28] QIAN, G., ZHU, C., YIN, C., et al., "Multiferroic properties of single-phase perovskite structure 0.8 $\mathrm{BiFeO} 3-0.2$ SrTiO 3 ceramics synthesized using the Pechini method", Journal of Electroceramics, v. 40, $\mathrm{n}$. 3, pp. 190-196, Maio 2018.

[29] CALLISTER JR., W.D., Ciência e engenharia dos materiais: uma introdução, $9^{a}$ ed., Rio de Janeiro, LTC, 2016. 
[30] LOPES, P.P., TICIANELLI, E.A. "Estudo do efeito de tratamentos térmicos em catalisadores de PtRu/C frente a reação de oxidação de hidrogênio na presença de CO”, Química Nova, v. 30, n. 5, pp. 1256, Jul. 2007.

[31] BRAGG, W.H., BRAGG, W.L., "The reflection of X-rays by crystals", The Royal Society Publishing, v. 88, n. 605, pp. 428-438, Jul. 1913.

[32] VERMA, S.RANI, S., KUMAR, S., KHAN, M.A.M., "Rietveld refinement, microstructural, optical and thermal parameters of zirconium titanate composites", Ceramics International, v. 44, n. 2, pp. 1653-1661, Fev. 2018.

[33] GRZEBIELUCKA, E.C., CHINELLATO, A.S. A.,TEBCHERANI, S.M., et al., "Synthesis and sintering of $\mathrm{Y}_{2} \mathrm{O}_{3}$-doped $\mathrm{ZrO}_{2}$ powders using two Pechini-type gel routes", Ceramics International, v. 36, n. 5, pp. 1737-1742, Jul. 2010.

[34] VASANTHAVEL, S.; KANNAN, S., "Structural investigations on the tetragonal to cubic phase transformations in zirconia induced by progressive yttrium additions", Journal of Physics and Chemistry of Solids, v. 112, pp. 100-105, Jan. 2018.

[35] KAYA, G., "Production and characterization of self-colored dental zirconia blocks", Ceramics International, v. 39, n. 1, pp. 511-517, Jan. 2013.

[36] DO AMARANTE, C.B., MULLER, A.H., PÓVOA, M.M., et al., "Estudo fitoquímico

biomonitorado pelos ensaios de toxicidade frente à Artemia salina e de atividade antiplasmódica do caule de aninga (Montrichardia linifera)", Acta Amazonica, v. 41, n. 3, 2011.

[37] KAPLAN, M., PARK, J., KIM, S.Y., et al., "Production and properties of tooth-colored yttria stabilized zirconia ceramics for dental applications", Ceramics International, v. 44, n. 2, pp. 2413-2418, Fev. 2018.

[38] KIM, H.K., KIM, S.H., "Optical properties of pre-colored dental monolithic zirconia Ceramics”, Journal of dentistry, v. 55, pp. 75-81, Dez. 2016.

[39] PÉREZ, M.M., HERRERA, L.L., CARRILLO, F., et al., "Whiteness difference thresholds in dentistry", Dental Materials, v. 35, pp. 292-297, Dez. 2019.

[40] KIM, H. K., "A study on the color distribution of natural teeth by age and gender in the Korean population with an intraoral spectrophotometer", Wiley Periodicals, v. 30, pp. 408-414, Set. 2018.

[41] Giovane Furlanetto, FURLANETTOODONTOLOGIA, https://furlanettoodontologia.com.br. Acessado em fevereiro de 2019.

\section{ORCID}

Naasson Matheus Pereira Balica Themistocles de Sousa Campelo Edson Cavalcante da Silva Filho Maria Rita de Morais Chaves Santos Rafaela Luiz Pereira Santos https://orcid.org/0000-0003-4088-0033

https://orcid.org/0000-0002-5725-5739

https://orcid.org/0000-0003-0988-2970

https://orcid.org/0000-0003-1618-7319

https://orcid.org/0000-0002-0240-2420 